\title{
UN MONASTERIO BARRIOALTINO Nuestra Señora del Prado
}

\author{
A MONASTERY IN "BARRIOS ALTOS"(District located in Lima) \\ "Nuestra Señora del Prado"
}

\author{
Dra. Arq. Adriana Scaletti ${ }^{1}$, Ing. Carolina Briceño ${ }^{2}$, \\ Dr. Ing. Rafael Aguilar ${ }^{3}$
}

\section{RESUMEN}

El presente artículo busca presentar los inicios de un trabajo interdisciplinar concentrado en los conjuntos monásticos de la zona de Barrios Altos en el centro histórico de Lima, Perú. El caso ejemplificativo tomado para la introducción general al tema es el conjunto de Nuestra Señora del Prado, fundado en 1640. El acercamiento se da desde las perspectivas de la historia, la arquitectura y la ingeniería estructural, y es también producto de un curso dictado y dirigido a arquitectos e ingenieros multidisciplinariamente en la Pontificia Universidad Católica del Perú.

\section{Palabras clave}

Monasterio, arquitectura, ingeniería, materiales, historia

\section{ABSTRACT}

This article seeks to present the beginnings of interdisciplinary work focused on monastic ensembles of the Barrios Altos area in the historic center of Lima, Peru. The exemplary case taken for the general introduction to the topic is the set of Nuestra Señora del Prado, founded in 1640. The approach is given from the perspectives of history, architecture and civil engineering, and is a product of a course taught by and directed towards architects and engineers at the Pontifical Catholic University of Peru.

\section{Keywords}

Monastery, architecture, engineering, materials, history

\section{INTRODUCCIÓN}

En la zona de Barrios Altos del centro histórico de la ciudad de Lima se concentra una parte significativa de lo que remane de los grandes conjuntos religiosos virreinales capitalinos, siendo los monasterios allí presentes de particular importancia para la historia de la ciudad y por extensión del país. Se cuentan aquí, por ejemplo, los de las Recoletas

\footnotetext{
1 Arquitecta por la Universidad Ricardo Palma de Lima, Magíster en Restauración de Monumentos por la Universidad La Sapienza de Roma, y Doctora en Gestión Cultural e Historia del Arte por la Universidad Pablo de Olavide de Sevilla (España). Profesora del Departamento de Arquitectura de la Pontificia Universidad Católica del Perú.

2 Estudiante de décimo ciclo de la Facultad de Ciencias e Ingeniería de la especialidad Ingenieria Civil de la PUCP. Asistente de investigación del grupo SHM PUCP (Structural Health Monitoring of Architectural and Archaelogical Heritage. Realiza trabajo de campo.

3 Doctor en Ingeniería Civil por la Universidad de Minho, Portugal (2010), Magíster en Ingeniería Civil por la Pontificia Universidad Católica del Perú (2006) e Ingeniero Civil por la Universidad Nacional de San Antonio Abad del Cusco (2004). Profesor del Departamento de Ingeniería de la Pontificia Universidad Católica del Perú.
} 
Descalzas de San José (fundado en 1603), Santa Clara (1606), Nuestra Señora del Prado (1640) o Nuestra Señora del Carmen Alto (1643).

Como es sabido, los monasterios -del griego monasterion, con raíz mono, es decir "uno solo"- como concepto y como edificios se instalan en el Perú muy temprano en el virreinato, existiendo como testimonio tanto de piedad local cuanto como sitios de refugio $y$ escuelas. Se diferencian de los conventos -del latín conventus o "asamblea" -en términos no solamente de su relación con la comunidad que los rodea- quienes habitan un convento entran y salen de él, en permanente contacto con el entorno- sino también por su configuración espacial y arquitectónica, que un sistema basado en circulaciones como "calles" y espacios semejantes antes que en ordenados claustros. Aunque relevantes en el proceso de evangelización tras la conquista española, y determinantes para la transición cultural necesaria ${ }^{4}$, los monasterios americanos fueron fundamentalmente de clausura y albergaron monjas que se "enterraban en vida" según colorida expresión de la época.

Y sin embargo este entierro era en el fondo una reproducción más o menos cerrada de la vida de la ciudad que rodeaba al monasterio: organizados formalmente como pequeñas ciudades, en los monasterios se encontraban todas las clases sociales y los prejuicios, divisiones y desigualdades del siglo. El monasterio era destino, claro, de quienes sentían la poderosa llamada de la fe, pero también desdichado encierro de hijas a quienes no podía casarse por falta de dote o de pretendientes apropiados, e incluso de mujeres que eran recluidas forzosamente por conflictos con la ley o por escándalos que ruborizasen a nerviosos parientes masculinos. Todas estas mujeres encontraban, por supuesto, distinto destino y distintos privilegios dentro de la ciudad cerrada del monasterio.
En una suprema ironía, los monasterios y sus habitantes constituían un tema de profundo interés para los residentes del mundo exterior: las elecciones abaciales, los ritos cotidianos, los aderezos y decorados de fiestas y de los vestidos de las propias monjas eran temas que se discutían en todas las esferas de la ciudad, y que causaban amargas discusiones y encendidas polémicas que más de una vez llevaban a verdaderos enfrentamientos cargados de violencia. ¿A qué podría deberse esto?

Pues además de los ocasionales conflictos que del siglo pasaban al interior a través de las -por lo menos en esto- humanísimas monjas y sus relaciones familiares y sociales antes de entrar en religión; pasando por alto las infaltables aunque veladas referencias a galanes entusiasmados con alguna joven y bella novicia; e ignorando por naturales las pequeñas y grandes discusiones de tenor teológico, el quid de la cuestión no puede ser más ordinario: el dinero.

Elaspectoeconómicoesfundamentalal estudiar cualquier conjunto religioso, pero sobre todo los monacales, de todo el virreinato peruano. La razón tras de esto está estrechamente ligada al funcionamiento regular de un monasterio cualquiera: como instituciones y como edificios físicos, dependen prácticamente del todo de las dotes de las monjas al asegurar su entrada en religión y luego, de la generosidad de las familias de estas monjas y sus amistades y por tanto del eventual provecho y ganancia que inteligentemente supieran sacar a partir de estos capitales iniciales 5 .

Burns ha trabajado este aspecto ampliamente para los ejemplares cusqueños, pero incluso la revisión más superficial de la documentación permite encontrar una situación semejante para la capital virreinal: los monasterios eran propietarios de casas, haciendas, granjas, tierras de cultivo, obrajes y un sinnúmero de etcéteras semejantes que eran cuidadosamente administrados por la Madre Abadesa y su tesorero de confianza, amén de la inevitable

\footnotetext{
4 Al respecto existen estudios muy interesantes, particularmente los de Kathryn Burns en Colonial Habits: Convents and the spiritual economy of Cuzco, Peru. Durham: Duke University Press, 1997.

5 En un esfuerzo por empezar la fundación del Prado en evangélica pobreza, vemos sin embargo que las monjas se trasladaron desde la Encarnación únicamente con mobiliario y no se habló de restitución de dotes.
} 
aunque ocasional supervisión del arzobispado y la común aunque protestada del prior de la correspondiente orden masculina.

La administración involucraba todo tipo de actividades comerciales, pero entre ellos el formato más común era el del censo.

Un censo era parte de un sistema de crédito organizado de manera que se circunnavegaran las consideraciones religiosas contra la usura: quien necesitara un préstamo entregaba quien pudiera permitirse darlo, normalmente un monasterio, un derecho de gravamen o uso sobre un bien o una propiedad que actuaba como garantía. El otorgante del censo entregaba una cantidad anual como si de una pensión se tratara, hasta que la cantidad prestada con el agregado de los réditos fueran devueltos. Pero si esto no se cumpliera, la propiedad o el bien quedaba en manos de quien otorgaba el préstamo y naturalmente esto se dio con frecuencia.

Para poder otorgar los préstamos en censo, los monasterios conseguían capital líquido con el arriendo de casas y tiendas -algunas obtenidas en previos censos- a lo que se agregaban las cantidades productos de la venta de las celdas para vivienda de las monjas $y$, por supuesto, las cantidades de las dotes al ingresar en religión.

Así, la dote no era un tema de poca monta: constituía el equivalente a la entregada en ocasión de un matrimonio de clase alta y en muchos casos encontramos compromisos en que era pagada en etapas por ser imposible para la familia de la religiosa darla en una sola parte. Existían sin embargo, algunas excepciones al pago de esta dote, que aunque raras se dieron en más de una ocasión: la más importante se refiere a que la candidata a monja dominase algún instrumento musical o tuviese una hermosa voz.

Esta provisión cobra sentido al entender que las monjas de más alto nivel dentro del escalafón del monasterio eran las de velo negro o de coro, encargadas por tanto de cantar el oficio divino entre otras obligaciones. En posiciones inferiores, la pirámide social al interior de la clausura incluía también a monjas de velo blanco, novicias, donadas, sirvientas y finalmente esclavas.

En términos arquitectónicos, los monasterios compartían algunos ambientes indispensables con los conventos: la sala capitular -lugar de reunión y asamblea-, el refectorio -para las comidas pero también para recibir las diarias lecturas edificatorias durante este tiempo de silencio forzoso-, la sala de profundis -cuyo nombre deriva del salmo 130, comenzando con un fúnebre "desde lo profundo clamo a ti Señor" y que hacía las veces de velatorio, entre otras cosas-, el huerto, las celdas, etc. Exclusivos para los monasterios de clausura encontramos otros espacios como el locutorio con su torno -único ambiente de conexión y relación de las monjas con el mundo exterior- o el coro bajo, enrejado hacia la iglesia que dominaba el conjunto, desde donde amigos y parientes pudieran quizás escuchar la voz de las monjas de la familia elevada en cantada oración a Dios.

Otra particularidad la daban las propias celdas, más complejas y elaboradas que las de sus similares conventuales. Se trata en estos casos de verdaderas casas en miniatura (pequeños "departamentos" comparables a ejemplares modernos, e incluso más grandes que algunos), con un ambiente de salita de estar, otro de dormitorio, incluso un diminuto patio con un horno o cocina en algunas ocasiones. Estas celdas eran el núcleo alrededor del cual muchas monjas organizaban verdaderas unidades familiares, con criadas, donadas y niñas a su cargo, prácticamente familias enteras en femenino. Existen incluso muchos documentos en el Archivo Arzobispal de Lima que detallan el sistema de propiedad y compraventa de estas celdas, y las importantes inversiones que algunas monjas y sus allegados hacían para la adquisición o el traspaso de las mismas.

Todos estos componentes los encontramos en Nuestra Señora del Prado -el monasterio que nos ocupa en esta ocasión- también conocido por la advocación titular de la iglesia como de la Expectación de Nuestra Señora, una devoción originalmente manchega que comenzó a ser venerada por las Agustinas Ermitañas Descalzas en la ermita del Cercado a fines del siglo XVI. 


\section{EL MONASTERIO DE NUESTRA SEÑORA DEL PRADO}

El monasterio en sí nació como una recolección donde las madres fundadoras, salidas del más antiguo monasterio de la Encarnación, buscaban encontrar mayor recogimiento $y$ estrecheces alrededor de la iglesia de Nuestra Señora del Prado. Esta era por entonces una capilla que funcionaba como templo auxiliar para la parroquia de Santa Ana en la actual plaza Italia, así que no fue nunca un gran conjunto que pudiera compararse a Santa Clara o al propio, inmenso complejo de la Encarnación, aunque poseía algunas piezas artísticas notables en su colección mueble y contó con el patrocinio del sexto arzobispo de Lima, don Pedro de Villagómez.

Los documentos conservados en el archivo del monasterio justifican la necesidad de fundarlo en una ciudad que ya contaba con una serie de recogimientos femeninos:

porque en esta ciudad de los Reyes, que es la mayor del Perú, después de seis conventos ŚsicS de monjas fundados, que todos por la mucha gente están no solo poblados, pero algunos demasiadamente llenos de religiosas, no puede ser inconveniente añadir uno y ese de recolección y fundándole religiosas de conocida virtud y ejemplo, hijas del más insigne de todos, cual es el de la Encarnación, donde la multitud de ellas pide bien semejante minoración, es especial para vida de mayor perfección y austeridad $^{6}$

Y enfatizan en mucho la importancia del origen del Prado desde el gran monasterio de la Encarnación, al cual se encuentra legado:

el número de monjas de la Encarnación, que ha crecido tanto que se tiene por demasiado, con que (el Prado) no se podrá juzgar fundación nueva, sino extensión y como división del dicho convento de la
Encarnación, que por ser el más antiguo $e$ ilustre de la ciudad y reino, parece razonable y justo que tenga recolección de su regla y hábito, como la tiene el de las Descalzas del Señor San José

Un tema de gran importancia al momento de establecer una fundación monacal era el de las cercas que rodearían el edificio: su función era principal, por supuesto, el impedir el acceso físico de quienes no contaran con autorización para acceder a la clausura, al tiempo que se aseguraba la permanencia de las religiosas en el encierro. Pero también se trataba de una necesidad simbólica, que representaba imaginariamente para la época una hipotética virtud ciudadana en cuanto se conservara la honra y virtud de las monjas escondidas a la vista.

Lo cierto es que no pudo darse el traslado de las fundadoras desde la Encarnación hasta estar seguros de cómo funcionaría este tema:

$y$ en la casa y sitio donde al presente se ha de fundar el monasterio de las monjas Recoletas de San Agustín de la advocación de Nuestra Señora de la Encarnación (del Prado) y lo vieron todo (...) y el Licenciado Jorge de Andrade Presbítero, que ha tomado a su cuidado el acomodar y disponer la dicha casa y sitio mientras se hacen las cercas y oficinas del dicho convento para poder habitar las fundadoras $^{8}$

Finalmente se logra el traslado y lentamente comienzan las obras para completar la construcción del conjunto monacal. Podemos suponer que se trató de inicios muy modestos, y que las primeras obras fueron las de los espacios comunitarios y los relacionados con actividades colectivas como el rezo del oficio divino o las comidas en el refectorio. Sabemos que se comenzó con la compra de algunas casas, hasta una casa y huerta que "linda con las paredes del pueblo del cercado", que luego

\footnotetext{
6 Archivo Monasterio de Nuestra Señora del Prado: Cédula Real para la fundación de Carmelitas Descalzas, 1639.

7 Idem.

8 Archivo Monasterio de Nuestra Señora del Prado: Auto del Cabildo - Vista de Ojos, 1640.

9 Archivo Monasterio de Nuestra Señora del Prado: Entrega de casa de don García de Heredia, 1648.
} 
se demolieron para hacer sitio a las nuevas celdas.

En 1654, el Arzobispo de Lima don Pedro de Villagómez, aparentemente enterado de "la falta de habitaciones convenientes para las religiosas, del deficiente estado del edificio y del desamparo en que se hallaba la comunidad"10, decidió constituirse en Patrón y comenzó con comprar por tres mil pesos una casa y un tambo en la esquina de los jirones Junín y Manuel Pardo, con la idea de construir allí los locutorios de la portería principal, continuando luego con la reedificación del monasterio.

De 1655 es un documento del Archivo Arzobispal de Lima donde en tres folios se hace una "Memoria sobre las obras de construcción realizadas por Juan de Mansilla, alarife, y Julián Sánchez en el Monasterio del Prado". Aquí se mencionan obras menores, pero de modo muy interesante se indica la cantidad de celdas preparadas para las religiosas y el costo total de su puesta en uso:

De 22 seldas, de rematarlas, enlucidos y blanqueados y soladas y subir los quartones y enbarados, y enpedrados los patiesillos, y apostamientos de puertas esta cada puerta por cinquenta y siete pesos y dos reales que monta - 10259 pesos $^{11}$

Poco después, en 1674, otro documento nos habla de nuevas obras necesarias para reparar la cubierta del monasterio, calculadas como un gasto de 700 pesos que se detalla en un inventario firmado por el alarife fray Diego Maroto. Lamentablemente, el documento está quemado por la acidez de la tinta empleada, pero un extracto nos da una idea de su contenido:

cubiertas de la yglesia con sus (ilegible) de cañas clabadas a trechos por (linea ilegible) con sus texas bidriadas en el cavallete y sobre el barro enlusida de cal y arena que lo mejor que se puede hacer en lo que toca a barro como se izo en su principio. Esto costara setecientos pesos con la misma cantidad de dichos setecientos que e consertado con Juan de Eysaguirre maestro albañil y alarife que lo aga en toda esta no de barro sino solado de ladrillo delgado que llaman (ilegible) prensado asentado con barro y rebocado con cal y puestas las cañas que faltan clabando otras asimismo (ilegible) con sus texas bidriadas asentadas con cal en el cavallete y que asentase con adobes el martinete (?) cuesta ${ }^{12}$

El terremoto de 1746 provocó el desplome del muro de clausura del lado derecho de la iglesia, destruyendo varias celdas. La abadesa Ignacia de la Encarnación solicitó y obtuvo entonces ampliar el área del monasterio para dejar más separación entre la cerca y las habitaciones, y elevó al respecto expediente en 1748:

que con el dicho monasterio linda un solar por la parte que hace al cercado (...) y siendo así que el dicho solar lo necesita el monasterio, no como adorno ni superflua extensión, sino para desahogar las tiendas $y$ refugios que puedan tener para los temblores por haber experimentado el grave riesgo a que se expusieron por la cortedad del sitio ${ }^{13}$

Al tratarse de una recolección de monjas Ermitañas Descalzas, al silencio y oración propios de la vida en clausura se agregaba un aspecto de reclusión individual que significó dar gran importancia a la celda de cada monja, que cada una debía construir, pero que debía ser en principio pobre y sencilla. Pronto, sin embargo, encontramos noticias de la suntuosidad con que vivían algunas monjas -aquí y en otros

10 E. Esteban. "Historia documentada del monasterio de Nuestra Señora del Prado". Lima: Cancillería Arzobispal, 1944, p. 119.

11 Archivo Arzobispal de Lima, Fondo Monasterio del Prado, II:8, 1655.

12 Archivo Arzobispal de Lima, Fondo Monasterio del Prado, III:3, 1674.

13 Archivo Monasterio de Nuestra Señora del Prado: petición del 8 de febrero de 1748. 
monasterios ${ }^{14}$ permitiéndose detalles como joyas personales, instrumentos musicales, elegantes telas y hasta pájaros cantores en sus celdas, cada vez más lujosas. Son de este período en el Prado también los elegantes azulejos del coro bajo: tras el enrejado, las monjas de velo negro rezaban, oían misa, cantaban y comulgaban rodeadas por la obra del azulejero criollo Juan del Corral -quien representó en los derrames de las ventanas a la Virgen Inmaculada y a Santa Mónica, por ejemplo- y una de las mejores sillerías monacales de la época. Bajo ellas, como irónico recordatorio de la fragilidad de la vida y sus lujos, se encuentra todavía hoy la cripta.

En una inspección de la Real Audiencia de 1666, se describe al conjunto en términos de gran riqueza:

el dicho convento ( $\underline{\text { sic }})$ se halla perfectamente acabado con iglesia muy competente y cuatro altares (se refiere a los retablos), y diferentes lámparas y adornos y colgaduras, todo de mucho valor, y en lo interior claustros, viviendas y huertas de toda comodidad, y en censos y posesiones seguras (...) y que el número de religiosas era hoy de veinte, y según la fundación ha de ser de treinta y tres ${ }^{15}$

Lo interesante de este caso específico, en términos de distribución espacial $y$ arquitectónica, es que a pesar de tratarse de un conjunto monacal, se reorganizó completamente desde el sistema de "callejuelas" tradicional de su origen para dar lugar a una organización en claustros que es la que se aprecia en la actualidad. Las celdas, que en un primer momento podía construir cada monja según su voluntad y medios económicos, se configuraron entonces en un modelo repetitivo que fue desde entonces prohibido modificar. Aunque no fue el único caso de esta transformación en Lima virreinal, es un ejemplo interesante y que ha sobrevivido con muchas dificultades, entre ellas la venta de una parte significativa del terreno del monasterio para poder permitirse las reparaciones posteriores al terremoto de 1940.

Hoy el Prado conserva apenas dos claustros, y uno de ellos apenas puede permitirse el nombre: son el Claustro Mayor -anexo a la iglesia y conteniendo las salas comunitarias principales, como es tradición-y el del Aromo, hoy muy degradado y sin galerías.

El Claustro Mayor responde precisamente al modelo tipológico: un patio con al centro una fuente -en simbólico recuerdo del árbol del conocimiento del paraíso- y cuatro caminos -los cuatro ríos del Edén- hacia las galerías que rodean por los cuatro lados el espacio. Estas galerías, calculadas para proteger a las religiosas durante momentos de reflexión y rezo a la par de sus desplazamientos, están construidas como es típico en estructuras semejantes en Lima: esto es, con columnas y falsos arcos con alma de madera, forrados con cañas y yeso. En las enjutas entre los arcos la decoración se observa hoy muy somera, con apenas algunas molduras lineales marcando la forma.

Las crujías del entorno de este claustro contienen, como se ha dicho, los ambientes tradicionales $y$ típicos en conventos $y$ monasterios: sala Capitular, sala del Miserere, etc.

La sala Capitular del Prado es un ambiente amplio con una cubierta de alfarje de elaborado tallado, que además contiene una enorme mesa de madera y una colección de pintura que incluye un impresionante Cristo y retratos de las fundadoras, abadesas y algunos importantes benefactores.

$14 \mathrm{Al}$ respecto véase, por ejemplo el manuscrito conservado en el Archivo Arzobispal de Lima relativo al monasterio de Las Descalzas de San Joseph indexado como VI: 82, sin fecha: Auto arzobispal, sobre las medidas a tomar con las porterías del monasterio, con respecto a los trajes, vestuario y decencia que debían poseer las religiosas que se acercaren a ellas y al locutorio, así como la disciplina de las porteras. $1 \mathrm{f}$.

15 Archivo Monasterio de Nuestra Señora del Prado: correspondencia entre la Reina Gobernadora doña Mariana de Austria a el Virrey Conde de Lemos o las personas a cuyo cargo fuere el gobierno de las provincias del Perú, 1668. 
La sala del Miserere, también con cubierta de alfarje y con grandes ventanas derramadas, contiene en uno de sus lados cortos un pequeño retablo barroco que preside el espacio. En los lados largos se encontraban bancas para las monjas durante los rezos de vigilia y también se asoman las puertas de los confesionarios, minúsculos ambientes ciegos con apenas espacio para el padre confesor. Desde esta sala se accede al coro bajo del conjunto, a los pies de la iglesia de la advocación. El coro bajo -tal vez el ambiente más interesante en este nivel-conserva aún, como mencionamos, la sillería de las monjas, la doble reja propia de su uso y un interesantísimo pavimento completo de azulejos. Tristemente, muchos de los azulejos están degradados y el esmalte en algunos ha desaparecido al punto que la imagen resulta irreconocible: es urgente su protección y limpieza. La cripta a la cual se accede desde aquí también ha sufrido importantes modificaciones, y ya no contiene ningún cuerpo.

El segundo claustro que se conserva hasta nuestros días es el llamado "del Aromo". El nombre actual responde a la presencia histórica de árboles frutales y flores en el sitio dentro de la imagen simbólica de verdor en los claustros como reflejo del paraíso terrenal, pero también con la idea de dar sombra y producir frutos que pudieran ser consumidos $y$ transformados en dulces y mermeladas por las monjas.

Existen evidencias de una galería cubierta también aquí, pero quedan apenas algunas cabezas de vigas y fustes de columnas desarmadas como testigos. Las crujías que determinan el contorno contienen celdas por todos los lados, muy completas en sus espacios pero también degradadas materialmente en pavimentos, cubiertas y muros. Muchas de ellas se encuentran en estado absolutamente precario, con numerosas grietas y lesiones estructurales y con faltantes importantes. La situación se ha agravado dada la disminución dramática de las vocaciones religiosas que puedan vivir aquí y proporcionar mantenimiento, aunque el conjunto ya no está más dedicado a la vida contemplativa: hoy están a cargo religiosas agustinas de vida activa, terciarias agustinas del Santísimo Salvador en un número muy reducido y que manejan un colegio moderno construido en el terreno inmediatamente adyacente a lo conservado.

\section{ANÁLISIS DEL SISTEMA ESTRUCTURAL Y DEL ESTADO DE DAÑO ENCONTRADO}

El sistema estructural de los conventos y monasterios limeños ubicados en el Centro Histórico está compuesto, en general, por muros de albañilería de adobe y quincha (en algunos casos se ha usado ladrillo para muros y vanos). Los entrepisos son de madera y la cubierta es liviana con una mezcla de madera, caña y barro.

El Monasterio de Nuestra Señora del Prado está compuesto por una serie de edificaciones cuyos sistemas estructurales corresponden precisamente a lo especificado. Para una mejor descripción estructural, el monasterio se ha separado en dos zonas en función a la altura y tipología de las edificaciones: el primero corresponde a la iglesia y el segundo al resto del complejo monástico.

En el caso de la iglesia, el sistema estructural está conformado por muros de adobe de $1.50 \mathrm{~m}$ de ancho y $10 \mathrm{~m}$ de altura los cuales están cimentados sobre mampostería de ladrillo. La cobertura es con una bóveda de cañón corrido de madera/caña/barro que va ubicada a lo largo de la nave iglesia y apoyada sobre los muros laterales. Existe también una cúpula de media naranja, ubicada antes del presbiterio, la cual está conformada por una serie de arcos de madera que descansan sobre las paredes. El hall de circulación, lateral a la iglesia, está compuesto por un sistema de arquerías de madera (recubiertas con una malla de gallinero y yeso para simular mayor sección) y el sistema de techos es de madera. En la Figura 1 se muestra la zona de la Iglesia y unas vistas de la nave principal y el sistema de techos. 


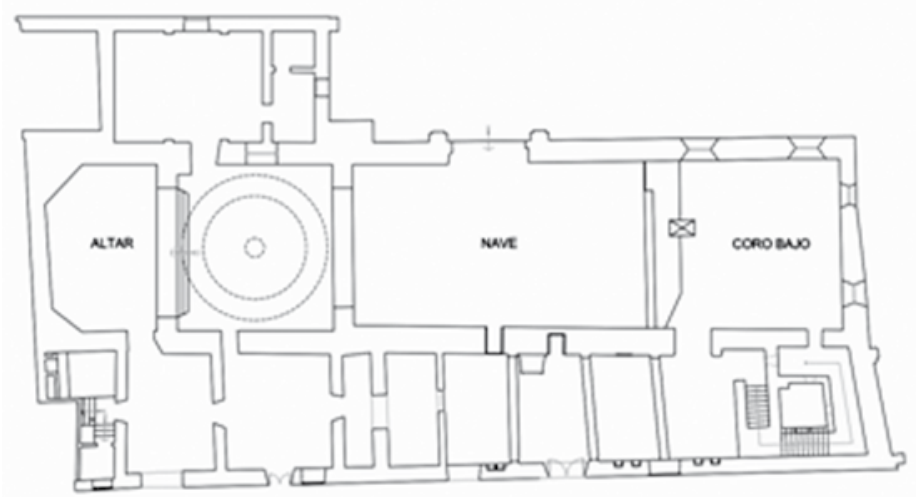

(a)

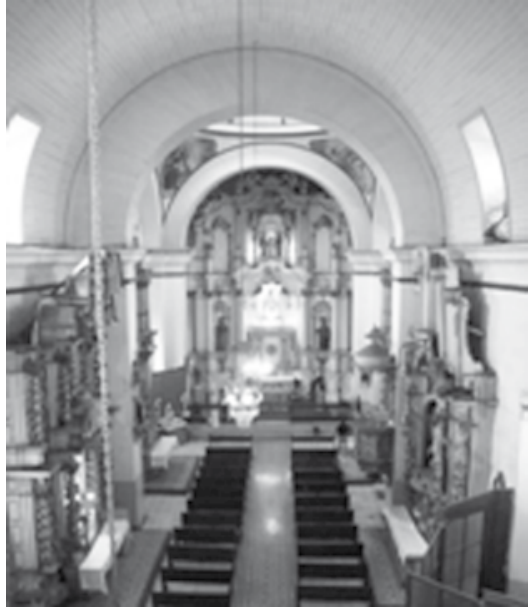

(b)

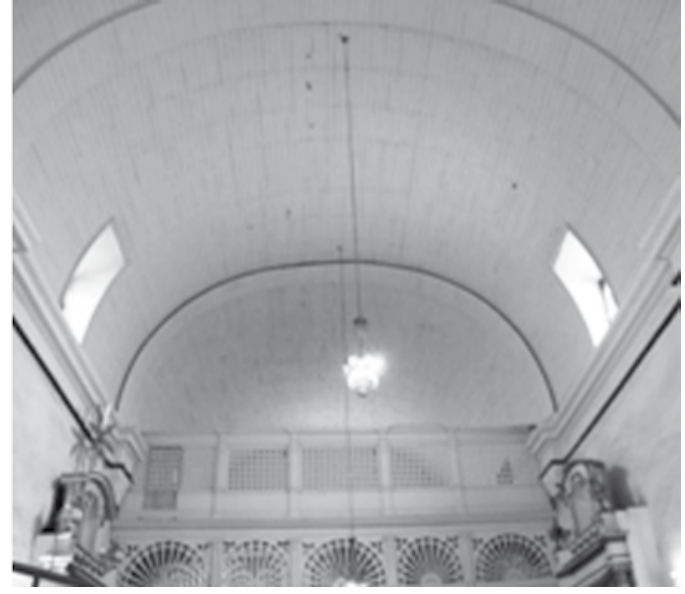

(c)

Figura 1: Iglesia del Monasterio Nuestra Señora del Prado. (a) Vista de planta (b) nave principal (c) Sisetma de techo de la iglesia, medio cañón corrido

En el caso de las edificaciones del resto del complejo monástico, son en general de un solo nivel y su sistema estructural está compuestos por muros de ladrillo, adobe o quincha con espesor variable entre $0.30 \mathrm{~m}$ y $1.0 \mathrm{~m}$. El sistema de cubiertas es con un entablado de madera apoyado sobre viguetas de madera. En la Figura 2 se muestra algunas de las edificaciones que integran el complejo monástico así como el sistema de cobertura.

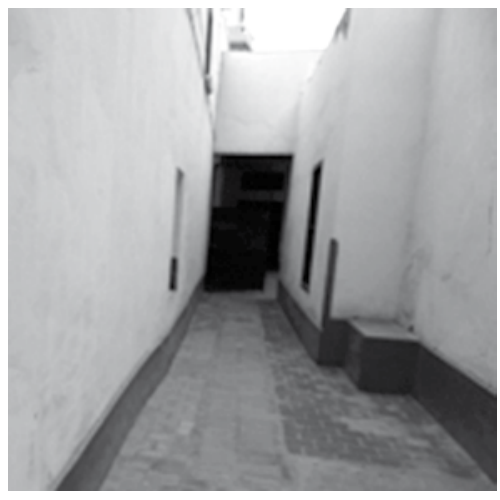

(a)

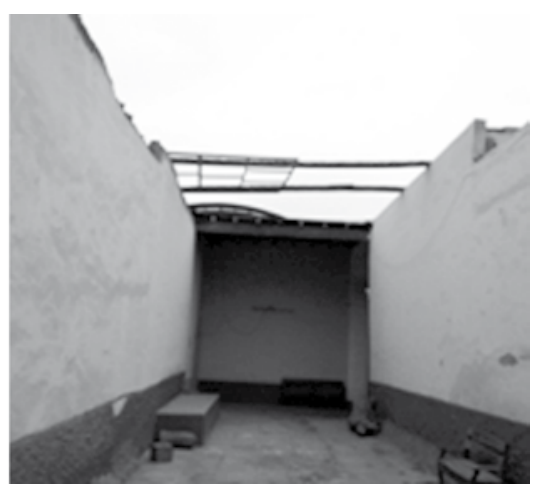

(b)

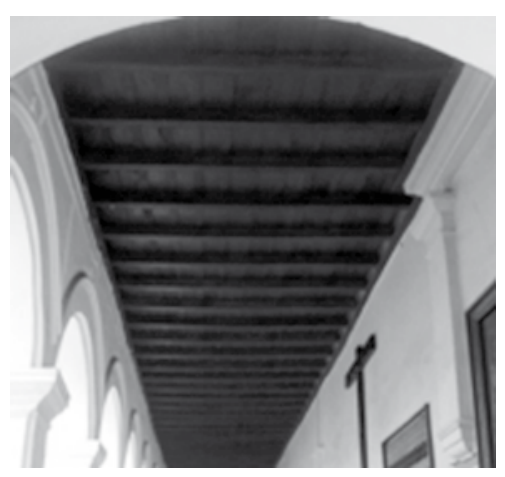

(c)

Figura 2: (a) Sector con muros de adobe. (b) Sector con muros de quincha (c) Sistema de techo del monasterio, viguetas y entablado de madera 
El monasterio, en general, tiene un avanzado estado deterioro debido a la falta de acciones planificadas de mantenimiento, los sismos de diferente intensidad sucedidos desde su construcción, incendios (uno devastador al final de siglo pasado) y en general al paso del tiempo. Recientemente, en la iglesia, se ha realizado algunas intervenciones destinadas a proteger sus muros, el coro alto y partes de la arquería del claustro principal. Las intervenciones han consistido en la reposición de materiales, retoques estéticos $y$ de pintura y una intervención mayor que incluye la construcción de pórticos de concreto armado en algunos sectores del hall lateral y coro. En general, existen también problemas relacionados al intemperismo, humedad, presencia de hongos, etc. En el caso del resto del complejo, ha habido intervenciones mayores de reposición de elementos estructurales caídos (muros y techos) en la zona de la sala capitular y un sector de salas comunitarias principales. El resto del complejo se encuentra estado de colapso parcial o total. La Figura 3 muestra un esquema del estado de daño del complejo monástico.

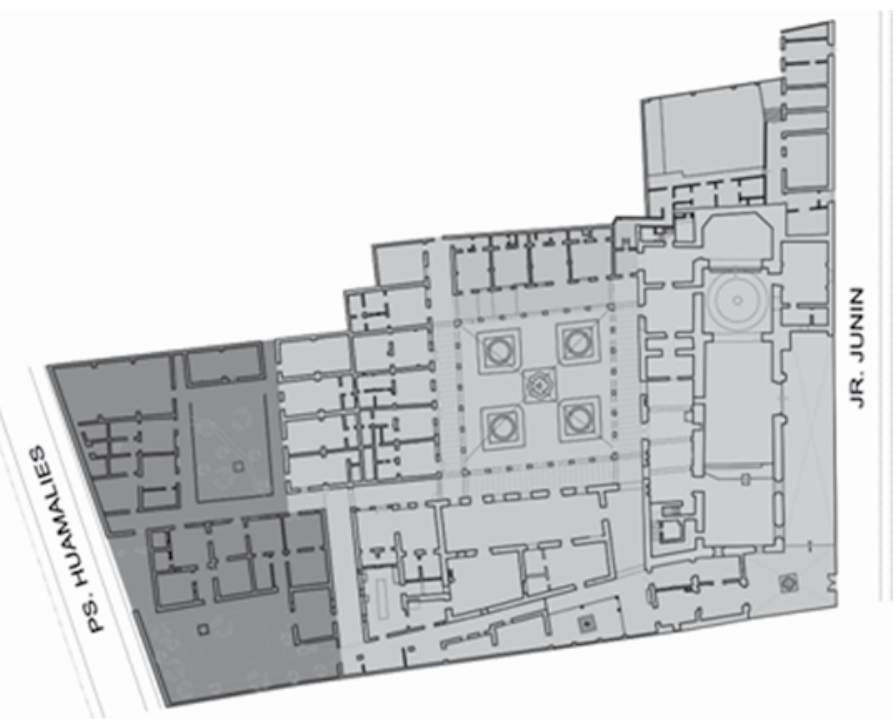

Zona colapso total $\square$ Iglesia $\square$ Zona colapso parcial $\square$ Zona daños menores

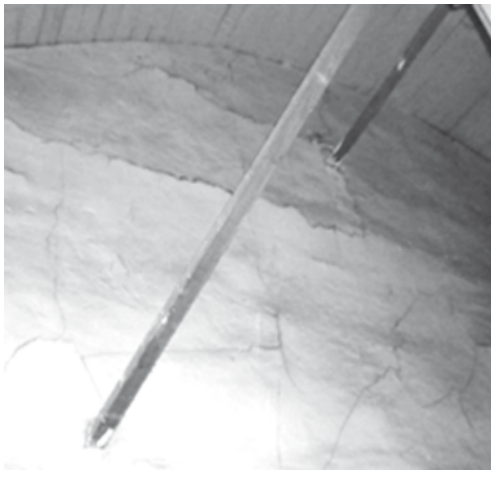

(a)

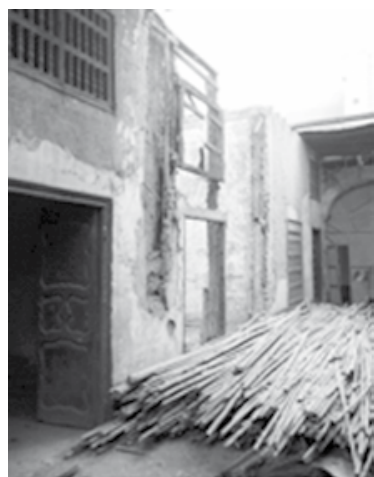

(b)

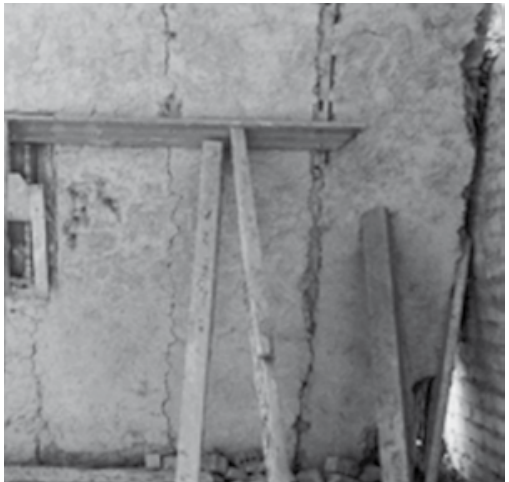

(c)

Figura 3: Planta general del complejo monástico sectorizada en función al estado de conservación estructural (a) Deterioro del tímpano de quimcha en la iglesia (b) En la zona de colapso parcial, celdas dañadas por el incendio (c) En la zona de colapso total, falla de muro de quincha por volteo

Como se verá más adelante, y de acuerdo a las cartas vigentes que indican la forma de cómo se debe intervenir las construcciones históricas, la propuesta de soluciones estructurales no debe responder a acciones de emergencia $u$ opiniones subjetivas. Por el contrario, una adecuada solución es producto de estudios detallados de diagnóstico para los cuáles se deben utilizar técnicas avanzadas experimentales y de análisis 
numérico. La ingeniería de conservación del patrimonio existente ha desarrollado en los últimos años una serie de herramientas de ensayos no destructivos y de análisis estructural específicamente para este tipo de construcciones.

Una forma de iniciar el proceso de diagnóstico estructural es primero, identificando los peligros a los que la estructura está sujeta y luego observando o imaginando las formas en las que la estructura va a fallar ante la ocurrencia de esos fenómenos. En el caso de la iglesia, se ha visto por ejemplo problemas potenciales que pueden ocurrir ante un evento sísmico. En este caso se ha identificado que los muros laterales y traseros, debidos a su gran altura, poco espesor y falta de contrafuertes, pueden fallar por fuera del plano. Además, se ha visto que una zona potencialmente vulnerable es también la del tímpano del muro testero ya que podría fallar de la misma manera (volteo) y esto ocasionaría pérdidas humanas $y$ materiales.

Para una mejor comprensión del comportamiento de la estructura de la iglesia, y para corroborar el diagnóstico inicial, se desarrolló un modelo computacional, preliminar y simplificado, en elementos finitos utilizando el programa SAP2000 (CSI, 2012). Los muros de adobe, la cobertura del pasadizo y el piso del coro se representaron mediante elementos tipo lámina, mientras que las vigas y columnas de madera mediante elementos lineales. La estructura del techo no fue modelada y en su lugar se aplicaron cargas equivalentes, tanto verticales y horizontales, que representan el peso y empuje que ejerce la bóveda de medio cañón corrido sobre las paredes de la iglesia y la cúpula sobre las secciones de pared que conforman su sistema de apoyo. La figura $4 a$ muestra un esquema del modelo numérico desarrollado. Los resultados de esfuerzos por cargas de gravedad (peso propio) no se muestran pero confirman lo esperado inicialmente con concentraciones de esfuerzos de compresión en la base de las paredes y la concentración de esfuerzos en las interfaces de conexión de muros y pórticos de concreto armado (los pórticos están ubicados en el hall lateral y fueron introducidos como elementos de refuerzo en la última intervención estructural ejecutada en ese sector). Los resultados del análisis modal realizado para estudiar la respuesta dinámica de la iglesia muestran que las formas modales correspondientes a los tres primeros modos de vibración (figura 4b) involucran movimientos fuera del plano de uno de los muros longitudinales. Este comportamiento confirma lo estimado inicialmente en lo referente a la vulnerabilidad de estos elementos estructurales.

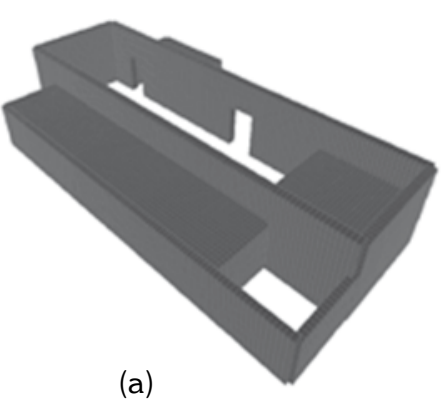

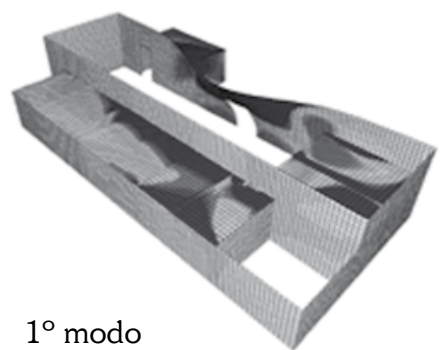

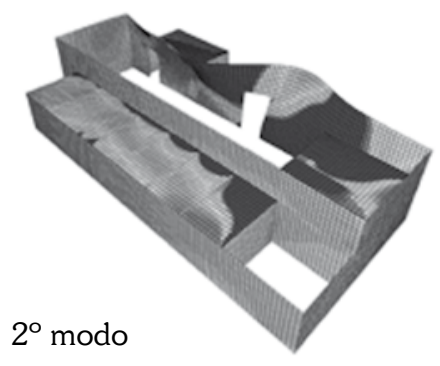

(b)

Figura 4: Análisis de elementos finitos de la iglesia. (a) Modelo computacional (b) Resultados del análisis global de la iglesia de Nuestra Señora del Prado: Tres primeros modos de vibración 


\section{INTERVENCIONES INTEGRALES DE EDIFICACIONES HISTÓRICAS}

Según el Ministerio de Cultura, en el país, existen aproximadamente 17000 monumentos históricos, entre complejos arqueológicos e inmuebles. Debido al alto valor cultural de estos, y al impacto no solo social, sino también económico que representaría su pérdida (este año se espera que los ingresos debido al turismo sean alrededor de 3600 millones de dólares) la aplicación de técnicas modernas y la participación de grupos interdisciplinares para la intervención estructural es de gran importancia.

La intervención en este tipo de construcciones debe seguir algunos criterios ya establecidos por las normas y cartas de conservación de monumentos (Leroy et al. 2002). Particularmente, son dos las etapas que se deben seguir para elaborar proyectos de intervención en edificaciones históricas. Estas etapas se resumen a continuación:

Etapa inicial de investigación y diagnóstico: Antes de realizar cualquier actividad sobre las construcciones históricas, es necesario que estas sean estudiadas desde el punto de vista histórico y estructural. En este caso, es necesario la recopilación histórica de los problemas reportados a lo largo del tiempo, de lasfuentes de daño, el registro detallado de patologías e identificación de materiales y sistema estructural en el campo, el desarrollo de campañas de experimentación en laboratorio para caracterización de materiales, el desarrollo de ensayos experimentales de carácter no destructivo en el sitio para la caracterización del sistema estructural y respuesta $y$, finalmente, análisis numéricos con modelos computacionales calibrados que representen lo que sucede en realidad con las construcciones.

Etapa final de propuesta de soluciones de intervención: La soluciones que se propongan deben contemplar el requisito de mínima intervención con el objetivo de preservar la construcción y mantener su originalidad sin que esto signifique que la intervención sea solo estética y de conservación. En el caso del problema sísmico, se hace necesario que la propuesta de intervención estructural consiga efectivamente mitigar el riesgo. En todos los casos se debe procurar que exista un equilibrio adecuado entre seguridad y autenticidad de la edificación El siguiente criterio fundamental para el planteamiento de soluciones es que estas deben ser reversibles de tal forma que se la pueda sustituir, en el futuro, por nuevas tecnologías más apropiadas sin comprometer la integridad del monumento.

\section{CONCLUSIONES}

El Monasterio de Nuestra Señora del Prado es un conjunto de larga historia y por lo mismo complicado y complejo: aquí como en otras edificaciones patrimoniales del Perú, se hace indispensable la participación interconectada de múltiples disciplinas, entre ellas por supuesto la arquitectura y la ingeniería civil. El ejercicio del curso de Temas de Ingeniería que fue el inicio de este trabajo sirvió para enfatizar la necesidad de trabajar en conjunto para poder efectivamente percibir la real problemática de los edificios, y poder actuar efectivamente por su preservación y transmisión integral al futuro. 


\section{REFERENCIAS}

Archivo Arzobispal de Lima (AAL).

Archivo del Monasterio de Nuestra Señora del Prado.

Angrand, L. (1972) Imagen del Perú en el siglo XIX. Lima: Milla Batres.

Armas Asín, F. (2007) Iglesias bienes y rentas: Secularización liberal y reorganización patrimonial en Lima 1820-1950. Lima: Instituto de estudios peruanos.

Basadre Grohmann, J. (2005) Historia de la República del Perú (1822-1933). 9a ed. Lima: El Comercio.

Benvenutto Murrieta, P. M., (2003) Quince plazuelas, una alameda y un callejón. Lima: Universidad del Pacífico - Edit. Laberintos.

Bromley, J. (1945) Evolución urbana de Lima. Lima: Consejo Provincial de Lima.

Burns, K. (2008) Hábitos coloniales. Los conventos y la economía espiritual del Cuzco. Lima: Quellca - Instituto Francés de Estudios Andinos.

Coloma Porcari, C. (2003) Patrimonio cultural inmueble del Perú. Lima: Instituto Latinoamericano de Cultura y Desarrollo.

CSI, (2012) Computer and Structures Inc. SAP2000. Disponible en Internet http://www.csiberkeley. $\mathrm{com} /$

Esteban, E. (1944) Historia documentada del monasterio de Nuestra Señora del Prado. Lima: Cancillería Arzobispal.

Fuentes, Manuel Atanasio (1867) Lima: apuntes históricos, estadísticos y de costumbres. Paris: Librería de Firmin Didot hermanos, hijos y ca.

García Bryce, J. (2000) Evolución urbana de Lima. En Homenaje al R.P. Dr. Antonio San Cristóbal. Lima y Arequipa: Universidad Nacional de Ingeniería y Universidad Nacional San Agustín.

Guerra Martiniére, M. y otros (Ed.) (1992) La mujer en la conquista y en la evangelización del Perú. Lima 1550-1650. Lima: Fondo Editorial Pontificia Universidad Católica del Perú y Universidad Femenina del Sagrado Corazón.

Gunther Doering, J. (1983) Planos de Lima 1613 - 1983. Lima: Municipalidad de Lima Metropolitana.

Laos, C. A. (1929) El culto Peruano. En Lima. La ciudad de los Virreyes - el libro peruano 18281829 (p. 354). Lima: Perú.

Leroy,T. Kimbro, E. y Ginel, W. (2002) Planning and Engineering Guidelines for the Seismic Retrofitting of Historic Adobe Structures, The Getty Conservation Institute, Los Angeles.

Marquina, R; Velarde, H; García, J; Pimentel, V. (1963) Informe de la comisión de calificación de los monumentos coloniales y republicanos - Tomo 6. En Junta Deliberante Metropolitana de 
Monumentos Históricos Artísticos y Lugares Arqueológicos de Lima. Lima: Municipalidad de Lima Metropolitana.

Portal Espinoza, I. (1924) Lima religiosa (1535-1924). Lima: Gil.

Riva Agüero y Osma, J. de la, (1932) Añoranzas. Lima: Impr. Torres Aguirre.

Rodríguez Cobos, L. (1979) La arquitectura como sistema simbólico: análisis de los estilos arquitectónicos neocolonial y moderno en la evolución urbana en Lima. Manuscrito no publicadotesis de grado en la Pontificia Universidad Católica del Perú.

Rugendas, J. M. (1975) El Perú romántico del siglo XIX. Lima: Carlos Milla Batres.

San Cristóbal Sebastián, A. (1988) Arquitectura virreynal religiosa de Lima. Lima: Studium.

San Cristóbal Sebastián, A (2003) Manuel de Escobar Alarife de Lima, 1640-1695. Lima: Instituto de Investigación, Facultad de Ingeniería y Arquitectura, Universidad de San Martín de Porres.

Sifuentes de la Cruz, L. E. (2004) Las murallas de Lima en el proceso histórico del Perú: ensayo acerca de la historia y evolución urbana de la ciudad de Lima entre los siglos XVII y XIX. Lima: Consejo Nacional de Ciencia, Tecnología e Innovación Tecnológica CONCYTEC.

Universidad Nacional de Ingeniería (1988) Inventario del patrimonio monumental inmueble de Lima: valles de Chillón, Rímac y Lurín. Lima: Convenio Facultad de Arquitectura, Urbanismo y Arte UNI y Fundación Ford.

Vargas Ugarte, R. (1959) Historia de la Iglesia en el Perú. Burgos: Imp. de Aldecoa.

Vargas Ugarte, R. (1960) Un monasterio limeño. Lima: Sanmartí.

Vargas Ugarte, R. (1968) Ensayo de un diccionario de artífices de la América meridional. Burgos: Imp. de Aldecoa.

Vargas Ugarte, R. (1972) Itinerario por las iglesias del Perú. Lima: Milla Batres. 